Transportation Research Forum

The Increasing Fatality Burden of Other Vehicle Occupants in U.S. Large Truck Accidents Author(s): Andrew M. Welki and Thomas J. Zlatoper

Source: Journal of the Transportation Research Forum, Vol. 43, No. 2 (Fall 2004), pp. 129-137

Published by: Transportation Research Forum

Stable URL: http://www.trforum.org/journal

The Transportation Research Forum, founded in 1958, is an independent, nonprofit organization of transportation professionals who conduct, use, and benefit from research. Its purpose is to provide an impartial meeting ground for carriers, shippers, government officials, consultants, university researchers, suppliers, and others seeking exchange of information and ideas related to both passenger and freight transportation. More information on the Transportation Research Forum can be found on the Web at www.trforum.org. 


\section{The Increasing Fatality Burden of Other Vehicle Occupants in U.S. Large Truck Accidents}

Since the late 1970s, occupant fatalities in U.S. large truck accidents have generally shifted from truck occupants to occupants of other vehicles (primarily autos and light trucks). This paper analyzes that shift by estimating a regression model of a death ratio (other vehicle occupant fatalities to truck occupant fatalities) using annual time-series data for the 19751999 period. The regression includes two ratio explanatory factors-car size to truck size, and nontruck vehicle miles to truck vehicle miles-and one non-ratio explanatory variable, the proportion of young drivers. The vehicle size ratio has a statistically significant negative relationship with the death ratio (i.e., an increase in the size ratio contributes to a shift from other vehicle occupant deaths to trucker deaths); and the vehicle miles ratio has a significant positive association with the fatality ratio (i.e., an increase in the vehicle miles ratio promotes a shift from trucker fatalities to other vehicle occupant fatalities). The proportion of young drivers has a significant negative relationship with the fatality ratio.

\section{by Andrew M. Welki and Thomas J. Zlatoper}

\section{INTRODUCTION}

Large truck accidents in the United States have serious repercussions. For example, during the 1990s they resulted in an annual death toll that ranged from 4,462 in 1992 to 5,398 in 1997 [National Highway Traffic Safety Administration (NHTSA) 2000, p. 30]. Also, Zaloshnja and Miller (2004) estimated that the average cost of a large truck crash is $\$ 59,153$ (in 2000 dollars). ${ }^{1}$

While the considerable number of annual fatalities due to large truck accidents is an obvious concern to all highway users, occupants of vehicles other than trucks face an additional issue associated with these crashes: The ratio of their death count to that of large truck occupants has risen over time. Based on data from NHTSA (2000, p. 30), from 1975 to 1999 the measure increased by $70.2 \%$. The current study investigates the dramatic growth in the ratio of occupant deaths.
This paper examines the issue of large truck safety by conducting a time-series analysis of U.S. fatalities resulting from large truck crashes since the mid-1970s. ${ }^{2}$ The first section notes trends in the major categories of these deaths, in occupant fatalities per unit of travel, and in the ratio of other vehicle occupant deaths to large truck occupant deaths. In the second section, a model that explains the ratio is specified. The third section describes the data set used in the analysis, and the fourth section provides regression estimates of the model. A summary and conclusions are provided in the final section.

\section{TRENDS IN LARGE TRUCK FATALITIES}

Since 1975 total deaths resulting from accidents involving large trucks have ranged from a high of 6,702 in 1979 to a low of 4,462 in 1992 (NHTSA 2000, p. 30). Figure 1 


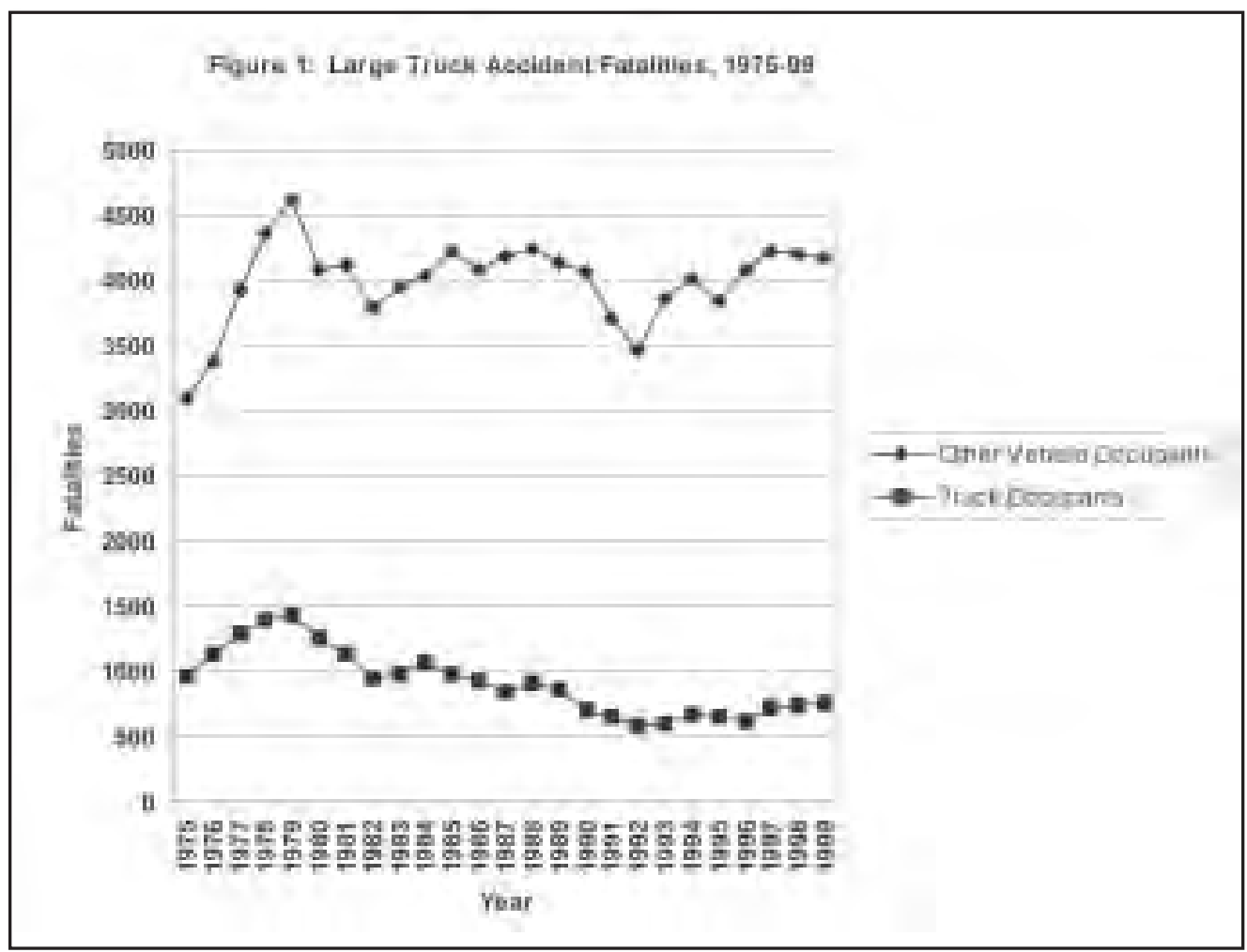

Source: NHTSA (2000)

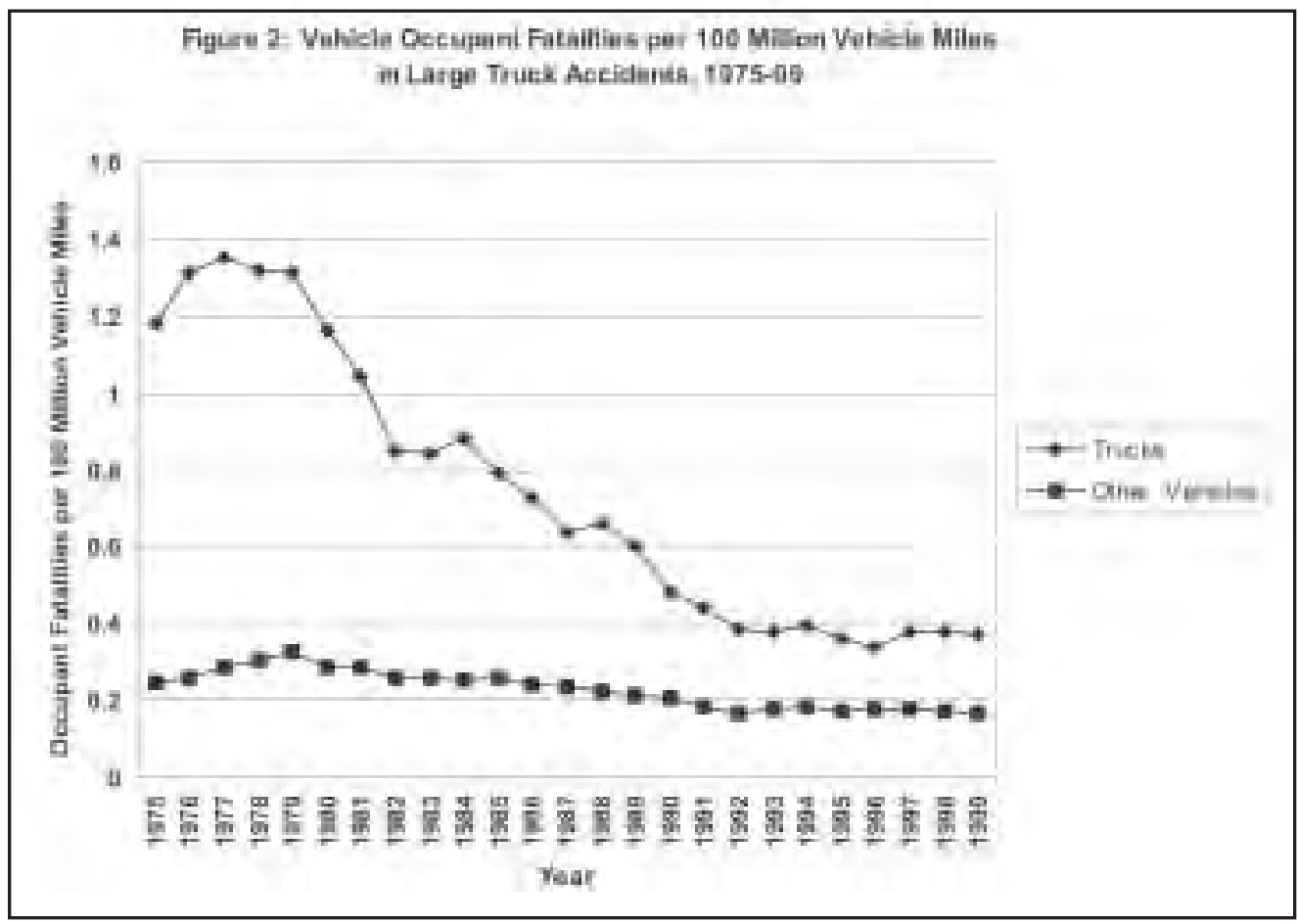

Source: FHWA (various years) and NHTSA (2000) 
provides plots of two categories of these fatalities: other vehicle occupants and truck occupants. Both plots peak in 1979. They demonstrate downward trends after that, although a notable upward movement in other vehicle occupant deaths is observable during the 1990s. ${ }^{3}$ Between 1975 and 1999, fatalities of other vehicle (mostly autos and light trucks) occupants and truck occupants have changed in opposite directions: The former increased by $34.3 \%$ (from 3,106 in 1975 to 4,170 in 1999), and the latter declined by $21.1 \%$ (from 961 in 1975 to 758 in 1999).

Figure 2 shows vehicle occupant fatalities per unit of travel (100 million vehicle miles) for vehicles involved in large truck crashes. After reaching maximums in the late 1970s, the fatality rates for both other vehicle occupants and truck occupants followed downward trends. Other vehicle occupant deaths per 100 million nontruck vehicle miles fell from 0.249 in 1975 to 0.168 in 1999 (32.5\%), while truck occupant fatalities per 100 million large truck vehicle miles decreased from 1.182 to 0.374 (68.4\%) over the same period. ${ }^{4}$ These rates show that highways have become safer for both categories of occupants; however, the decline in fatality risk has been less for other vehicle occupants than for truckers (32.5\% vs. 68.4\%).

Information over time on the mix of occupant fatalities in large truck accidents is provided in Figure 3. The ratio of other vehicle occupant deaths to truck occupant deaths trends upward from a minimum of 2.989 in 1976 to a maximum of 6.581 in 1996. In other words, in the late 1970s there were about three other vehicle occupant fatalities for every truck occupant death, but by the early to middle 1990s there were more than six other vehicle fatalities for every truck death. This indicates that over time occupant

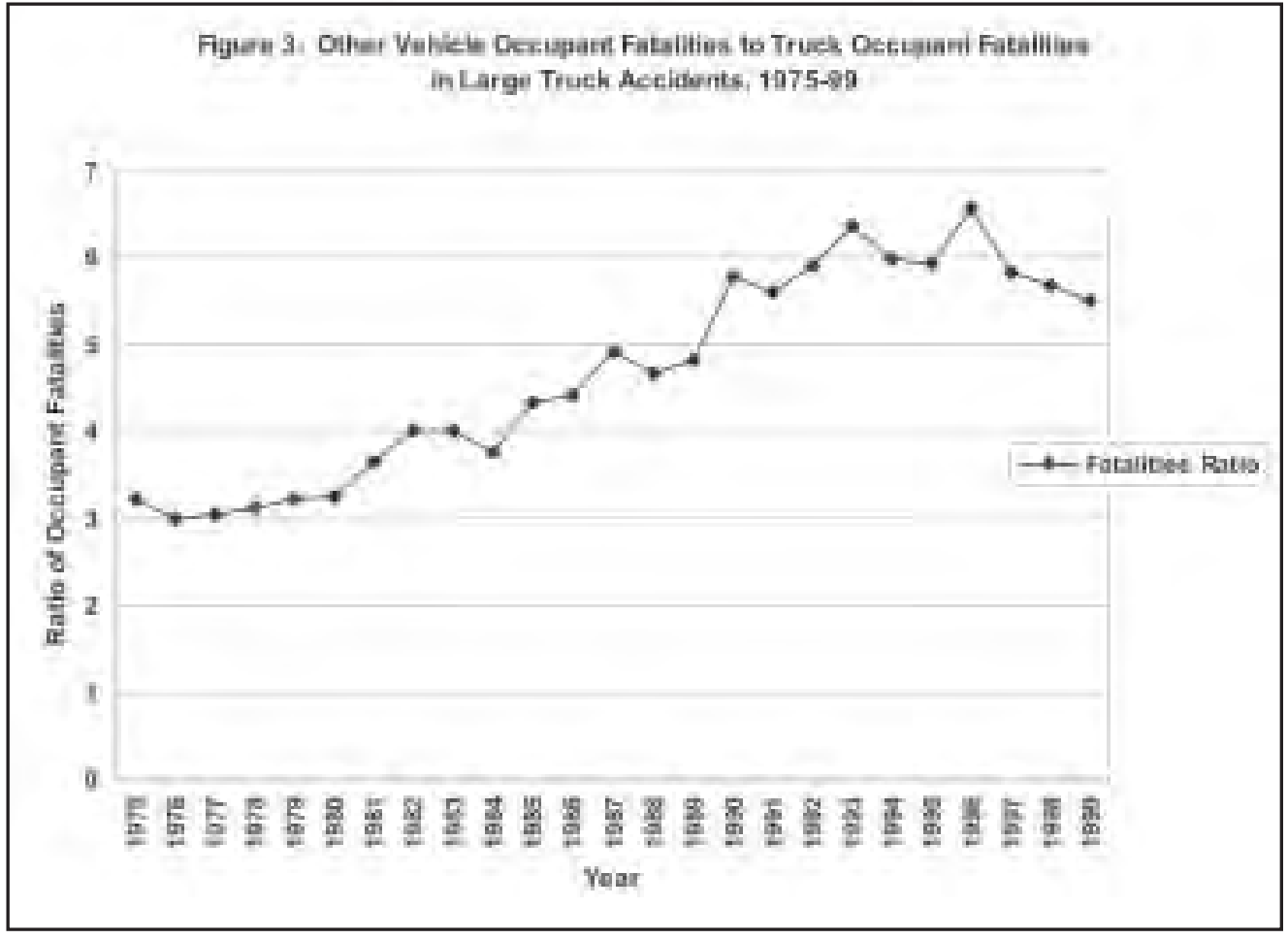

Source: NHTSA (2000) 
deaths in large truck crashes have shifted from truck occupants to other vehicle occupants.

\section{MODEL}

The model presented here posits that the occupant death ratio in large truck accidents depends, among other things, on variables that account for a vehicle factor (size) and two driver factors (amount of travel and age). ${ }^{5}$ Its general form is:
(1) OVOC/TRK = f(CARSZ/TRKSZ, NTRKVM/TRKVM, YOUTH) where

OVOC/TRK = ratio of other vehicle occupant deaths to large truck occupant deaths; ${ }^{6}$

CARSZ/TRKSZ = ratio of car size to large truck size;

NTRKVM/TRKVM = ratio of nontruck vehicle miles to large truck vehicle miles;

YOUTH = young drivers.

The ratio of car size to large truck size is expected to be negatively related to the ratio of other vehicle occupant deaths to large truck occupant deaths. Loeb, Talley, and Zlatoper (1994, pp. 28-29) cited statistical studies providing evidence that, on balance, vehicle size has a lifesaving effect. ${ }^{7}$ In the event of an accident, other things being the same, larger vehicles should provide more protection for their occupants but place the occupants of other involved vehicles at greater risk. Thus, an increase (decrease) in car size relative to truck size should lower (raise) the number of other vehicle occupant deaths relative to large truck occupant deaths.

The ratio of nontruck vehicle miles to truck vehicle miles is expected to be positively related to the ratio of other vehicle occupant deaths to large truck occupant deaths. Loeb, Talley, and Zlatoper (1994, p. 25) referenced several studies reporting statistically significant positive relationships between travel volume variables and measures of total and/ or vehicle-occupant fatalities. Thus, for a given number of vehicles using the road, an increase (decrease) in the amount of travel by other vehicles relative to trucks should put other vehicle occupants at greater (less) risk of accident and death.

Loeb, Talley, and Zlatoper (1994, p. 24) contained several time-series statistical studies that found direct relationships between highway death measures and youth-ful drivers. Therefore, to account for another potentially important determinant of large truck safety, such driving is included as an explanatory factor. However, the impact of young drivers on the ratio of other vehicle occupant fatalities to large truck occupant fatalities is uncertain a priori. The nature of this factor's relationship with other vehicle occupant deaths and large truck occupant deaths could be the same; but the proportional change caused by the factor may vary across the two death categories.

\section{DATA}

Estimation of the model in Equation (1) uses annual U.S. data for 1975-99. The dependent variable OVOC/TRK is measured by other vehicle occupant deaths divided by truck occupant deaths. The source for this information is NHTSA (2000).

CARSZ/TRKSZ is the ratio of a measure of average car size to a measure of average truck size. The measures for car size and truck size were the inverse of average miles per gallon for cars and trucks, respectively. ${ }^{8}$ The data for the measures came from the Federal Highway Administration (FHWA 1997a, 1997b, 1998, and 2000). ${ }^{9}$

NTRKVM/TRKVM is the ratio of nontruck vehicle miles (in millions) to large truck vehicle miles (in millions). The nontruck measure is the difference between total vehicle miles for all motor vehicles and large truck vehicle miles. FHWA (1997a, 1997b, 1998, 1999, and 2000) is the source for the total vehicle mile data, and NHTSA (2000) is the source for the large truck vehicle mile values.

YOUTH is the proportion of licensed drivers who are 24 years old and younger. This information came from FHWA (1997a, 1997b, 1998, 1999 and 2000). Table 1 provides summary statistics of the variables used in the model estimation. 
Table 1: Summary Statistics of Variables

\begin{tabular}{|l|c|c|}
\hline VARIABLE & MEAN & STD. DEV. \\
\hline OVOC/TRK & 4665 & 185 \\
\hline CARSZ/TRKSZ & 0325 & 0040 \\
\hline NTRKVM/TRKVM & 13384 & 0767 \\
\hline YOUTH & 0176 & 0033 \\
\hline
\end{tabular}

Empirical Measures Used for Variables:

OVOC/TRK = other vehicle occupant deaths divided by large truck occupant deaths

CARSZ/TRKSZ = inverse of average miles per gallon for cars divided by inverse of average miles per gallon for trucks

NTRKVM/TRKVM = nontruck vehicle miles divided by large truck vehicle miles

YOUTH = proportion of licensed drivers who are 24 years old and younger

\section{ESTIMATION RESULTS}

A log-log specification of the general formulation given in Equation 1 was estimated by ordinary least squares regression. ${ }^{10}$ Table 2 provides the estimation results. It is noteworthy that the three independent variables explain more than $95 \%$ of the variation in the death ratio. Based on a Durbin-Watson test, there is no evidence of first-order serial correlation.

CARSZ/TRKSZ has an expected negative relationship with OVOC/TRK, and NTRKVM/TRKVM has an anticipated positive relationship with the death ratio. Both of these relationships are statistically significant. ${ }^{11}$ These results indicate that an increase in car size relative to truck size leads to fewer other vehicle occupant deaths per truck fatality. They also suggest that when the nontruck travel volume grows faster than the truck travel volume, there are more other vehicle occupant deaths per truck fatality.

YOUTH has a statistically significant negative relationship with the death ratio. Over the time period of this study, the proportion of young licensed drivers trended downward. ${ }^{12}$ Assuming both types of occupant fatalities are directly associated with this proportion, the negative relationship between the death ratio and YOUTH would result if other vehicle occupant fatalities fall relatively less than truck occupant deaths. An explanation for the decline in both types of occupant fatalities is that an older driving population- in both cars and trucks - creates a more experienced, and hence safer, driving environment.

To assess the impact of other factors on the death ratio, several additional log-log regressions were estimated. In each instance one explanatory variable was added to the specification in Equation 1. These explanatory variables were: economic activity, alcoholic intoxication while driving, vehicle speed, and motor carrier deregulation. ${ }^{13}$ There is evidence cited in Loeb, Talley, and Zlatoper (1994) that these factors are determinants of highway accidents and fatalities. However, the expected impacts of these non-ratio measures on the death ratio analyzed in this study were uncertain a priori. As it turned out, except for economic activity, all of the additional factors were statistically insignificant; and in the regressions including the factors, the three variables on the right side of Equation 1 were significant and of the same signs reported in Table 2. In the regression in which it was included, economic activity, as measured by the unemployment rate, was significant and positively related to the death ratio, but CARSZ/TRKSZ and NTRKVM/TRKVM became insignificant, although they retained the same signs as in Table 2. The insignificance of variables in the additional regressions was probably due largely to multicollinearity, as many of the additional regressors were highly correlated with relative vehicle size and vehicle miles. 


\section{SUMMARY AND CONCLUSIONS}

This paper studies truck safety by analyzing annual U.S. time-series data for the 19751999 period on fatalities in large truck crashes. It finds that totals in two categories of these deaths-other vehicle occupant and truck occupant-have tended to decline since the late 1970s, although a notable upward movement in other vehicle occupant fatalities occurred during the 1990s. Of interest in this paper is the result that over the last two decades vehicle occupant deaths in large truck accidents have shifted from truck occupants to other vehicle occupants.

The ratio of other vehicle occupant fatalities to truck occupant fatalities is analyzed using regression analysis. The model includes two ratio explanatory factors—car size to truck size, and nontruck vehicle miles to truck travel vehicle milesand a driving population characteristic. The vehicle size ratio has a statistically significant negative relationship with the death ratio; while the vehicle miles ratio has a significant positive association with the fatality ratio. A higher proportion of young drivers has a significant negative relationship with the fatality ratio.

The findings from the regression suggest that over time the changing size disparity between trucks and cars, and the bigger difference between nontruck and truck travel volumes have shifted fatality risk in large truck accidents from truckers to nontruckers. Public officials should keep the vehicle size results in mind when considering adoption of policies that would either permit larger truck sizes and loads or reduce car sizes.

Table 2: Regression Estimates of Other Vehicle Occupant Deaths to Large Truck Occupant Deaths, 1975-99

\begin{tabular}{|l|c|c|}
\hline \multicolumn{2}{|c|}{ Dependent Variable: L(OVOC/TRK) } \\
\hline \multicolumn{1}{|c|}{$\begin{array}{c}\text { Independent } \\
\text { Variable }\end{array}$} & $\begin{array}{c}\text { Expected } \\
\text { Sign }\end{array}$ & $\begin{array}{c}\text { Estimated } \\
\text { Coefficient }\end{array}$ \\
\hline Intercept & & $\begin{array}{c}-3.319 \# \# \\
(-3.300)\end{array}$ \\
\hline L(CARSZ/TRKSZ) & - & $-0.781^{* *}$ \\
\hline & & $(-2.680)$ \\
\hline L(NTRKVM/TRKVM) & + & $0.797^{*}$ \\
\hline & & $(2.383)$ \\
\hline $\mathrm{L}($ YOUTH) & $?$ & $-1.069 \# \#$ \\
\hline & & $(-6.507)$ \\
\hline $\mathrm{n}$ & & 25 \\
\hline $\mathrm{R}^{2}$ & & 0.951 \\
\hline Adjusted R ${ }^{2}$ & & 0.944 \\
\hline $\mathrm{D}-\mathrm{W}$ Statistic & & 1.745 \\
\hline
\end{tabular}

Notes:

All variables are measured in natural logarithms. $\mathrm{t}$ statistics are reported in parentheses.

* Significant at .05 level (one-tail test)

** Significant at .01 level (one-tail test) \#\# Significant at .01 level (two-tail test) 


\section{Endnotes}

1. Zaloshnja and Miller (2004) accounted for the large truck crash costs for medical services, emergency services, property damage, lost productivity, and pain and suffering because of death or injury.

2. According to NHTSA (2000, p. 195), large trucks are "Trucks over 10,000 pounds gross vehicle weight rating, including single unit trucks and truck tractors.”

3. Greater detail on other vehicle occupant deaths may be of interest. For example, 4,170 of the 5,362 individuals killed in large truck accidents during 1999 were other vehicle occupants. The classification of the other vehicle occupant fatalities by vehicle type (and percentage) was: passenger car (60.3\%), light truck (35.8\%), motorcycle (2.8\%), bus (0.3\%), and other/unknown (0.8\%). [Federal Motor Carrier Safety Administration (2001, p. 16)]

4. For the period 1975-1999, Lyman and Braver (2003) discuss trends in occupant deaths in large truck crashes per 100,000 population, per 10,000 licensed drivers, per 10,000 registered trucks and per 100 million vehicle-miles of travel.

5. The model was specified based on research results of truck accident studies reported in the literature. Loeb, Talley, and Zlatoper (1994, Chapter 4) provide a survey of research on determinants of truck accidents. Another source of information on determinants of truck accidents is the Large Truck Crash Causation Study (NHTSA, 2002), a data collection project conducted by NHTSA and the Federal Motor Carrier Safety Administration. In addition, Harwood et al. (2003) synthesize the knowledge and practice pertaining to the accommodation of heavy vehicles on highways.

6. The ratio of non-trucker deaths to trucker deaths could rise if the number of non-trucker deaths held constant and the number of truck fatalities fell. As suggested by a referee, the dependent variable was reformulated as follows: ratio of other vehicle occupant deaths/non-truck vehicle miles to large truck occupant deaths/large truck vehicle miles. The logarithm of the reformulated dependent variable was regressed on the logarithms of the vehicle size ratio and YOUTH. The regression results were as follows:

\begin{tabular}{lcr} 
Variable & Regression Coefficient & t-statistic \\
\cline { 2 - 3 } Intercept & -3.925 & -32.034 \\
L(CARSZ/TRKSZ) & -0.859 & -3.341 \\
L(YOUTH) & -1.064 & -6.579
\end{tabular}

Since the signs, coefficient magnitudes, and statistical significance of the estimated coefficients were very similar to those in Table 2, the vehicle occupant deaths were not adjusted by vehicle miles.

7. McCarthy (1995) reported statistically significant evidence that total, urban, and rural fatalities per vehicle mile decrease with car size and increase with truck size.

8. McCarthy (1992) used these measures for car and truck size. He found a large negative correlation between the number of truck axles and miles per gallon, which suggests that the inverse of miles per gallon is a good measure for truck size.

9. The truck data are for single-unit 2-axle 6-tire or more trucks and combination trucks.

10. As noted by Loeb, Talley, and Zlatoper (1994, p. 38), the log-log specification is often utilized in regression studies of highway deaths. This specification allows for interactive effects among independent variables in the model. In particular, it assumes that the effect on the dependent variable of a change in an independent variable depends on the levels of the other independent variables. Also, the coefficients in the log-log specification are elasticities. 
11. In this paper "statistical significance” refers to significance at a level of $5 \%$ or less.

12. YOUTH declined by $40.7 \%$ (from 0.226 in 1975 to 0.134 in 1999).

13. Economic activity was measured by the unemployment rate reported by the U.S. Bureau of the Census (1980, 1998, and 2000). Alcoholic intoxication while driving was approximated by per capita ethanol consumption figures taken from Nephew et al. (2002). Vehicle speed was represented by a dummy variable equal to zero in the years of the data set (1975-86) that a national speed limit of 55 mph was in effect and one in all later years when many states had speed limits of $65 \mathrm{mph}$ or higher. Deregulation was measured by a dummy variable equal to zero in 1975-79 and one in 1980 and all subsequent years when motor carrier deregulation has been in effect.

\section{References}

Harwood, D.W., I.B. Potts, D.J. Torbic, and W.D. Glauz. Highway/Heavy Vehicle Interaction: A Synthesis of Safety Practice. Commercial Truck and Bus Safety Synthesis Program. Washington, DC: Transportation Research Board, 2003. http://trb.org/publications/ctbssp/ctbssp_syn_3.pdf

Loeb, P.D., W.K. Talley, and T.J. Zlatoper. Causes and Deterrents of Transportation Accidents: An Analysis by Mode. Quorum Books, Westport, CT, 1994.

Lyman, S. and E.R. Braver. "Occupant Deaths in Large Truck Crashes in the United States: 25 Years of Experience.” Accident Analysis and Prevention 35, (2003): 731-739.

McCarthy, P. "Highway Safety Implications of Expanded Use of Longer Combination Vehicles (LCVs).” Paper presented at the $6^{\text {th }}$ World Congress on Transport Research; Lyon, France; June 29July 3, 1992.

McCarthy, P. "The 1982 Surface Transportation Assistance Act (STTA): Implications of Relaxed Truck Weight and Size Limits for Highway Safety.” Transport Policy 2 (2), (1995): 107-117.

Nephew, T.M., G.D. Williams, H. Yi, A.K. Hoy, F.S. Stinson, and M.C. Dufour. Apparent Per Capita Alcohol Consumption: National, State, and Regional Trends, 1977-99, Surveillance Report \#59, National Institute on Alcohol Abuse and Alcoholism, 2002. http://www niaaa nih.gov/publications/ surveillance59/CONS99.htm

U.S. Bureau of the Census. Statistical Abstract of the United States: 1980. Washington, DC: U.S. Government Printing Office, 1980.

U.S. Bureau of the Census. Statistical Abstract of the United States: 1998. Washington, DC: U.S. Government Printing Office, 1998.

U.S. Bureau of the Census. Statistical Abstract of the United States: 2000. Washington, DC: U.S. Government Printing Office, 2000.

U.S. Department of Transportation, Federal Highway Administration. Highway Statistics: Summary to 1995. FHWA-PL-97-009. Washington, DC:, 1997a.

U.S. Department of Transportation, Federal Highway Administration. Highway Statistics: 1996.

FHWA-PL-98-003. Washington, DC:, 1997b.

U.S. Department of Transportation, Federal Highway Administration. Highway Statistics: 1997.

FHWA-PL-98-020. Washington, DC:, 1998. 
U.S. Department of Transportation, Federal Highway Administration. Highway Statistics: 1998. Washington, DC:, 1999. http://www.fhwa.dot.gov///ohim/hs98/hs98page.htm

U.S. Department of Transportation, Federal Highway Administration. Highway Statistics: 1999. Washington, DC:, 2000. http://www fhwa.dot.gov///ohim/hs99/index htm

U.S. Department of Transportation, Federal Motor Carrier Safety Administration. Large Truck Crash Facts 1999. DOT-MC-01-104. Washington, DC:, 2001.

U.S. Department of Transportation, National Highway Traffic Safety Administration. Large Truck Crash Causation Study: Interim Report. DOT HS 809 527. Washington, DC:, 2002.

U.S. Department of Transportation, National Highway Traffic Safety Administration. Traffic Safety Facts 1999: A Compilation of Motor Vehicle Crash Data from the Fatality Analysis Reporting System and the General Estimates System. DOT HS 809 100. Washington, DC:, 2000.

Zaloshnja, E. and T.R. Miller. “Costs of Large Truck-Involved Crashes in the United States.” Accident Analysis and Prevention 36, (2004): 801-808.

Andrew M. Welki is an assistant professor of economics at John Carroll University. He received his Ph.D. in economics from the Pennsylvania State University. Welki's research interests include transportation safety, economic education, and sports economics. His work has been published in The Journal of Business Education, Managerial and Decision Economics, and other journals.

Thomas Zlatoper is professor of economics at John Carroll University. He received his Ph.D. in economics from Northwestern University. Zlatoper's research interests include transportation safety, airline economics, and sports economics. His work has been published in the Journal of Transport Economics and Policy, Applied Economics, Accident Analysis and Prevention, Managerial and Decision Economics, and other journals. He co-authored the book Causes and Deterrents of Transportation Accidents: An Analysis by Mode. 